\title{
Selection of an Appropriate Depressant in Flotation Separation of Molybdenum Oxide from Fluorapatite
}

\author{
Jiandong Liu, Binbin Peng, Liping Zhao, Fengwei Bai and Zhiwu Lei *D \\ School of Resource Environment and Safety Engineering, University of South China, Hengyang 421001, China; \\ 2015002060@usc.edu.cn (J.L.); Peng2867@126.com (B.P.); zhaoliping20020818@163.com (L.Z.); \\ bfw1232021@163.com (F.B.) \\ * Correspondence: lzw_1407@163.com
}

Citation: Liu, J.; Peng, B.; Zhao, L.; Bai, F.; Lei, Z. Selection of an Appropriate Depressant in Flotation Separation of Molybdenum Oxide from Fluorapatite. Minerals 2021, 11, 1110. https://doi.org/10.3390/ $\min 11101110$

Academic Editors: William Skinner and Kirsten Claire Corin

Received: 28 August 2021

Accepted: 5 October 2021

Published: 10 October 2021

Publisher's Note: MDPI stays neutral with regard to jurisdictional claims in published maps and institutional affiliations.

Copyright: (c) 2021 by the authors. Licensee MDPI, Basel, Switzerland. This article is an open access article distributed under the terms and conditions of the Creative Commons Attribution (CC BY) license (https:/ / creativecommons.org/licenses/by/ $4.0 /)$.

\begin{abstract}
The depressive efficiency of sodium silicate, sodium hexametaphosphate, and tartaric acid on the flotation separation of molybdenum oxide from fluorapatite were examined using cetylpyridinium chloride (CPC) as the collector. The corresponding depression mechanisms of all three depressants were studied with the use of laboratory measurements. Individual mineral flotation tests and adsorption studies showed that all these depressants have a higher depression effect on fluorapatite than molybdenum oxide. Sodium hexametaphosphate has the strongest depression effect on fluorapatite and can reduce the flotation recovery as low as less than $20 \%$. Infrared spectroscopy and zeta potential tests proved the rationality of the flotation results, indicating that when CPC was used as a collector, the effect of sodium hexametaphosphate on the surface of molybdenum oxide was smaller than that on fluorapatite. The adsorption of hexametaphosphate on the surface of fluorapatite was determined to be physical adsorption.
\end{abstract}

Keywords: molybdenum oxide; fluorapatite; flotation; depressant; sodium hexametaphosphate

\section{Introduction}

The nickel-molybdenum ore resources were found mainly in specific regions of China, such as Guizhou, Hunan, Zhejiang, and the Eastern Yunnan Province, usually associated with other metals, such as, $\mathrm{Se}, \mathrm{Re}, \mathrm{Au}, \mathrm{Ag}, \mathrm{Pt}, \mathrm{Pd}$, etc.) [1-4]. The molybdenum minerals in the Ni-Mo ore are mainly jordisite, but the mine also contains various other materials composed of molybdenum and sulfur in different ratios [5-7]. The molybdenum mineral distribution pattern varies throughout the region, with certain areas showing grainy, reticular, vein-like, nodular, or zonal distributions, or even distributions in conjunction with pyrite $[8,9]$. The nickel minerals observed in this area are mainly nickel sulfide and gersdorffite. The molybdenum minerals in the Ni-Mo ore are mostly amorphous in structure [10]. Elements with similar chemical properties (such as molybdenum, tungsten, nickel, vanadium, and iron) chemically combine with sulfur and carbon [11,12]. No uniform morphology was observed [13]. As a result, it is difficult to separate valuable metal elements from one another [14]. Nickel and molybdenum minerals are flakes or irregular shapes. The target minerals are closely combined with gangue minerals, the diameter of which are only ten micrometers. The hardness of the nickel and molybdenum minerals varies greatly. Most of the useful minerals are hard ground minerals. A large amount of fluorapatite and mica contained in the ore crumbles easily, only a small selection of flotation reagents is available for the flotation of minerals with these characteristics. Compositional analysis of the NiMo ore indicates that it contains certain amounts of molybdenum oxide with minimal floatability, which adversely affects the recovery rate of the elemental molybdenum. A suitable depressant was selected for the depression of gangue minerals and is important for increasing the recovery rate of elemental molybdenum.

Fluorapatite is one of the main gangue minerals in Ni-Mo ore. Inorganic acids (phosphoric acid, sulfuric acid) are usually used as the pulp $\mathrm{pH}$ regulators to inhibit apatite 
flotation in a weak acid environment. Dong [15] used iron ions to improve the depressive efficiency of tartaric acid on the flotation separation of scheelite from calcite. Tartaric acid and $\mathrm{Fe}^{3+}$ were co-adsorbed on the surface of calcite by reacting with the calcium ion in calcite. This phenomenon indicates that tartaric acid was a very effective calcium mineral depressant. Abdel-Khalek [16] reported that $\mathrm{PO}_{4}{ }^{3-}$ exhibited characteristic adsorption of $\mathrm{Ca}^{2+}$ on the surface of apatite in an acidic system, leading to a depression effect on apatite flotation. $\mathrm{H}_{3} \mathrm{PO}_{4}$ can be used as both a pulp $\mathrm{pH}$ adjustor and apatite inhibitor by preventing the upward flotation of apatite attached to bubbles [17]. This role is mainly attributed to a decrease in the $\mathrm{Ca}^{2+}$ concentration in the acidic solution, which promotes the adsorption or formation of $\mathrm{CaHPO}_{4}$ on the surface of apatite, thereby hindering contact between reagent ions and apatite. Rodrigo [18] found that sodium hexametaphosphate and sodium silicate dispersants increase copper and molybdenum recoveries, rendering mineral particles more negatively charged by removing magnesium and calcium hydroxy complexes from mineral particles. As a result, heterocoagulation between chalcopyrite/molybdenite and mica particles is reduced, leading to high recoveries.

Therefore, this work is focused on the flotation separation of molybdenum oxide and fluorapatite, by the addition of a more appropriate depressant for fluorapatite flotation. In this regard, the depression effects of different depressants such as sodium silicate, sodium hexametaphosphate, and tartaric acid were investigated systematically, aiming at obtaining the most suitable depressant for fluorapatite flotation.

\section{Experimental}

\subsection{Samples and Reagents}

Pure molybdenum oxide and fluorapatite samples were used in this study. The former was purchased from a chemical reagent factory in Shanghai, with a granularity of $0.63 \mathrm{~mm}$, and the latter was purchased from the Mineral Specimens Company of Shuiyuanshanchang in Beijing.

Molybdenum oxide is an industrial reagent containing $\mathrm{MoO}_{3}$ of $99.6 \%$ purity and was used in this study following characterization. The samples were ground in a porcelain mill (rotation grinding) for 1-2 min and then sieved to collect the $-0.074 \mathrm{~mm}-+0.038 \mathrm{~mm}$ fraction for the flotation tests. Samples of fluorapatite were handpicked, crushed with a jaw crusher into grains measuring approximately $3 \mathrm{~mm}$, ground in a porcelain mill (rotating grinding) for 3-4 $\mathrm{min}$, and sieved to select the $-0.074 \mathrm{~mm}-+0.038 \mathrm{~mm}$ fraction for the flotation tests.

Cetylpyridinium chloride (CPC) of analytical quality was used as the collector for the flotation tests. $\mathrm{HCl}$ and $\mathrm{NaOH}$ solutions were used to adjust the $\mathrm{pH}$ value of the system. Analytical grade sodium silicate, sodium hexametaphosphate, and tartaric acid were used as the depressants. Deionized ultrapure water was used throughout the experiments.

\subsection{Methods}

\subsubsection{Flotation Experiments}

Individual mineral micro-flotation tests were performed in a $40 \mathrm{~mL}$ flotation machine (Weikeduo XFG II, ganzhou, China) at a constant impeller speed of $1860 \mathrm{rpm}$. For each test, parallel experiments were set, the experimental results were determined as the average of the two sets of experiments, and the difference between the experimental results of the two sets of experiments was not more than $2 \%$. A $2 \mathrm{~g}$ mineral sample was placed into the flotation cell, $35 \mathrm{~mL}$ of distilled water was added and stirred for $1 \mathrm{~min}$, and $\mathrm{HCl}$ or $\mathrm{NaOH}$ was added and stirred for $1 \mathrm{~min}$ to adjust for the desired value. Then, the depressant was added and stirred for $1 \mathrm{~min}$. Finally, the collector was added, and the flotation was performed for $3 \mathrm{~min}$. The floating and non-floating fractions were separately dewatered, dried, and weighed for the assessment. 


\subsubsection{Adsorption Studies}

The effects of $\mathrm{pH}$ and the depressant on the adsorption characteristics of the collectors on the mineral surface were measured using a TU-1810 UV-visible spectrophotometer.

For each test, $2.0 \mathrm{~g}$ of sample ore was placed into a $40 \mathrm{~mL}$ flotation cell and stirred for $2 \mathrm{~min}$. Next, a flotation reagent was added under the same mixing conditions used in the individual mineral flotation tests. A centrifuge (5417R, Eppendorf, Hamburg, Germany) was used to separate the pulp over $15 \mathrm{~min}$. The resulting supernatant was used for testing.

Adsorption of the flotation reagents on the mineral surface could be calculated according to the following formula:

$$
\Gamma=\left(\mathrm{C}_{0} \mathrm{~V}_{0}-\mathrm{C}_{\mathrm{i}} \mathrm{V}_{0}\right) / 1000 \mathrm{G},
$$

where:

$\Gamma$ is adsorption of flotation reagents on the mineral surface, $\mathrm{mol} / \mathrm{g}$

$\mathrm{C}_{0}$ is the original concentration of flotation reagents in solution, $\mathrm{mol} / \mathrm{L}$

$\mathrm{V}_{0}$ is the volume of the solution, $\mathrm{mL}$

$\mathrm{C}_{\mathrm{i}}$ is the concentration of flotation reagents in the supernatant, $\mathrm{mol} / \mathrm{L}$

$\mathrm{G}$ is the weight of sample ore, $\mathrm{g}$

\subsubsection{Infrared Spectroscopic Analysis}

The samples were prepared by the following procedure. The pure mineral was ground in an agate mortar. One-half of the sample ore was used for infrared spectroscopic analysis, and the second half was placed into a beaker with $35 \mathrm{~mL}$ of deionized water and flotation reagents and then stirred for $5 \mathrm{~min}$ before being filtered. The remaining solid was placed in a vacuum dryer to produce a mixture of the mineral and the flotation reagents. A NEXUS670 Fourier transform infrared spectrometer (670FT-IR, NEXUS, Madison, USA) was used to test the three samples: (1) the mineral, (2) the reagent, and (3) a mixture of 1 and 2.

\subsubsection{Determination of Zeta Potentials}

The zeta potential analysis was performed using a Delsa-440SX analyzer (Delsa-440SX, Beckman Coulter, Brea, CA, USA). A suspension containing a mass fraction of $0.01 \%$ of molybdenum oxide mineral or fluorapatite mineral was dispersed in a beaker by ultrasonication and then stirred in a magnetic stirring apparatus for $5 \mathrm{~min}$. On the other hand, $1.6 \times 10^{-2} \mathrm{~mol} / \mathrm{L}$ of sodium hexametaphosphate was added to the two suspensions and stirred for $2 \mathrm{~min}$, respectively, to prepare the mixed samples of minerals and depressants. After the $\mathrm{pH}$ was measured, the suspensions were immediately transferred to a square sample vessel to record the zeta potential readings.

\section{Results and Discussion}

\subsection{Floatability Tests of Minerals}

The purities of the molybdenum oxide and fluorapatite used in this study were $99.60 \%$ and $99.00 \%$, respectively. Using CPC as the collector, the effects of depressants on the flotation behaviors of molybdenum oxide and fluorapatite at different $\mathrm{pH}$ values were studied; the results are shown in Figures 1-3.

The three depressants had little effect on the flotation recovery of the molybdenum oxide at $\mathrm{pH} 2-6$, as indicated by the recovery rates of $73 \% \sim 78 \%$. However, the flotation recovery of fluorapatite was greatly decreased in the presence of the depressants. Figure 1a shows that the flotation recovery of fluorapatite decreased by approximately $10 \%$ compared to that without sodium silicate. Figure $1 b, c$ shows that the flotation recovery of fluorapatite decreased after adding sodium hexametaphosphate or tartaric acid, and their recovery rate was only $10 \% \sim 20 \%$ over the entire $\mathrm{pH}$ range. 

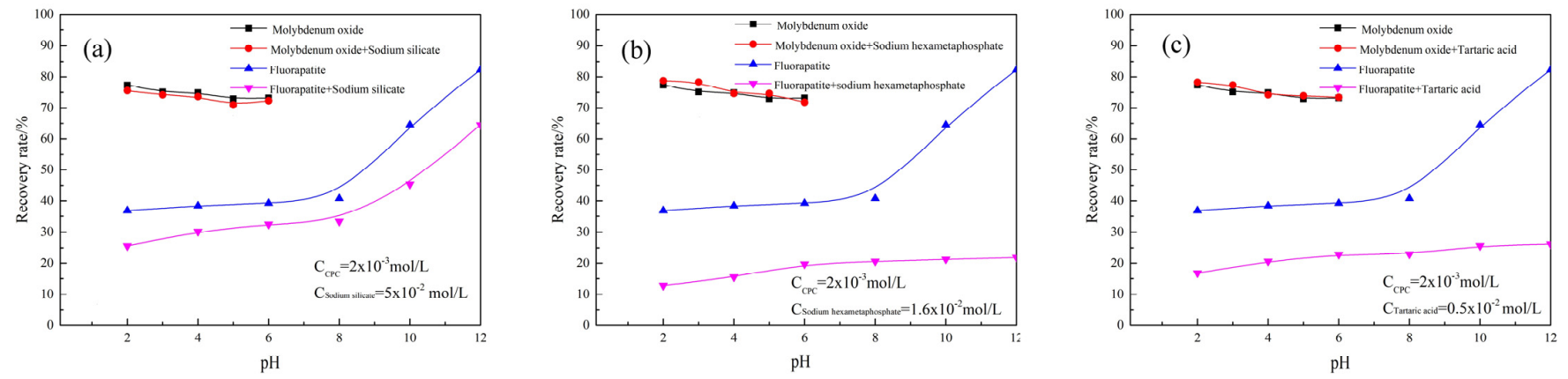

Figure 1. Effect of the three depressants on the floatability of molybdenum oxide and fluorapatite at different $\mathrm{pH}$ values: (a) sodium silicate; (b) sodium hexametaphosphate; (c) tartaric acid.

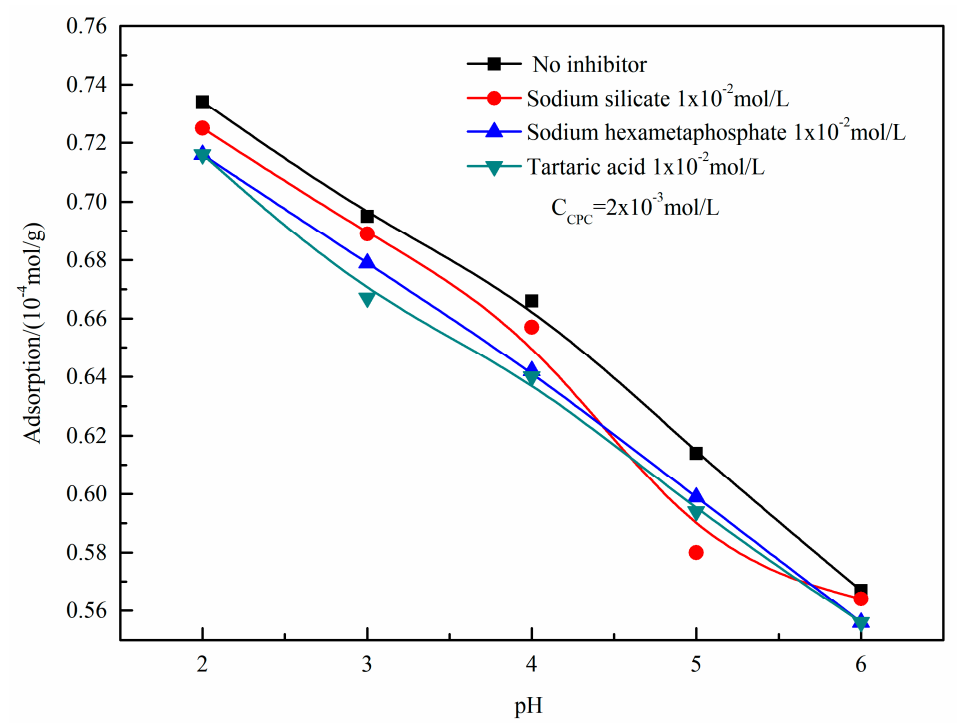

Figure 2. Effect of three inhibitors on the adsorption of CPC on the surface of molybdenum oxide at different $\mathrm{pH}$ values.

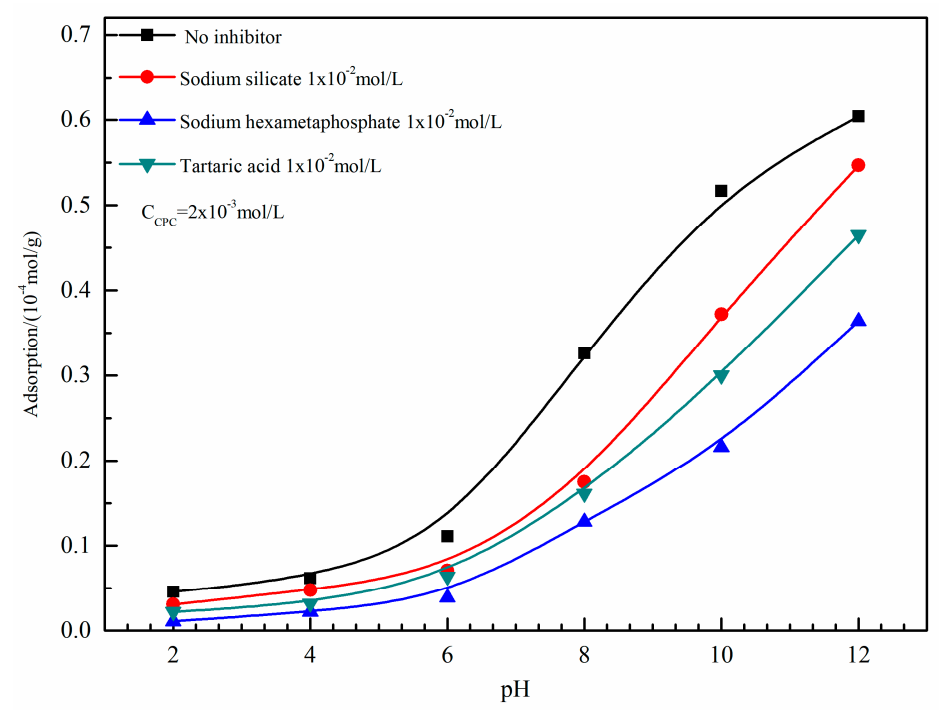

Figure 3. Effect of inhibitors on the adsorption of CPC on the surface of fluorapatite at different $\mathrm{pH}$ values. 
In summary, the flotation results show that the sodium hexametaphosphate effectively suppressed the flotation of fluorapatite and thus could be used as a selective depressant in the flotation separation of molybdenum oxide and fluorapatite with CPC as the collector.

\subsection{Solubility Equilibrium Analysis of Fluorapatite}

Figure 1 shows that when the $\mathrm{pH}$ level was higher than 8 , the flotation recovery of fluorapatite with CPC rose steadily, primarily due to the solubility equilibrium. The equilibrium reactions in the saturated aqueous solution of fluorapatite [17] are listed in Table 1.

Table 1. Equilibrium reactions of fluorapatite in a saturated aqueous solution $\left(25^{\circ} \mathrm{C}\right)$.

\begin{tabular}{cc}
\hline Chemical Equation & Equilibrium Constant (log k) \\
\hline $\mathrm{Ca}_{10}\left(\mathrm{PO}_{4}\right)_{6}(\mathrm{~F})_{2}+6 \mathrm{H}^{+}=10 \mathrm{Ca}^{2+}+6 \mathrm{PO}_{4}{ }^{3-}+2 \mathrm{~F}^{-}$ & 11.8 \\
$\mathrm{Ca}^{2+}+\mathrm{H}_{2} \mathrm{PO}_{4}{ }^{-}=\mathrm{CaH}_{2} \mathrm{PO}_{4}{ }^{+}$ & 1.1 \\
$\mathrm{Ca}^{2+}+\mathrm{HPO}_{4}{ }^{2-}=\mathrm{CaHPO}_{4(\mathrm{aq})}$ & 2.7 \\
$\mathrm{CaHPO}_{4(\mathrm{~S})}=\mathrm{Ca}^{2+}+\mathrm{HPO}_{4}{ }^{2-}$ & -7.0 \\
$\mathrm{Ca}^{2+}+2 \mathrm{OH}^{-}=\mathrm{Ca}(\mathrm{OH})_{2(\mathrm{aq})}$ & 2.77 \\
$\mathrm{Ca}^{2+}+\mathrm{OH}^{-}=\mathrm{CaOH}^{+}$ & 1.4 \\
$\mathrm{Ca}^{2+}+\mathrm{PO}_{4}{ }^{3-}=\mathrm{CaPO}_{4}^{-}$ & 6.46 \\
$\mathrm{Ca}^{2+}+\mathrm{F}^{-}=\mathrm{CaF}^{+}$ & 1.9 \\
$\mathrm{CaF}_{2(\mathrm{~S})}=\mathrm{Ca}^{2+}+2 \mathrm{~F}^{-}$ & -10.4 \\
$\mathrm{H}_{2} \mathrm{PO}_{4}{ }^{-}+\mathrm{H}^{+}=\mathrm{H}_{3} \mathrm{PO}_{4}$ & 2.15 \\
$\mathrm{H}_{2} \mathrm{PO}_{4}{ }^{-}=\mathrm{H}^{+}+\mathrm{HPO}_{4}{ }^{2-}$ & -7.20 \\
$\mathrm{HPO}_{4}{ }^{2-}=\mathrm{H}^{+}+\mathrm{PO}_{4}{ }^{3-}$ & -12.35 \\
\hline
\end{tabular}

The relationship between the individual concentrations of each dissolving group and the lattice ion concentrations can be determined based on the equilibrium formulas and the equilibrium constants. In the saturated fluorapatite solution, the isoelectric point, pI, can be determined by the negative logarithm of the corresponding lattice ions, I, when $\mathrm{CaF}^{+}$and $\mathrm{H}_{2} \mathrm{PO}_{4}{ }^{-}$have the same concentration. The calculated $\mathrm{pI}$ values are as follows: $\mathrm{pF}=4.5 ; \mathrm{pHPO}_{4}=5.8 ;$ and $\mathrm{pCa}=4.2$. All values are very similar to the test values $(\mathrm{pF}=4.6$, $\mathrm{pHPO}_{4}=5.2$, and $\mathrm{pCa}=4.4$ ); therefore, the ions in fluorapatite were determined to include $\mathrm{Ca}^{2+}, \mathrm{F}^{-}, \mathrm{CaF}^{+}, \mathrm{HPO}_{4}{ }^{2-}$, and $\mathrm{H}_{2} \mathrm{PO}_{4}$.

\subsection{Adsorption Studies}

Figure 2 shows the effects of inhibitors on the adsorption of CPC on the surface of molybdenum oxide at different $\mathrm{pH}$ values. It can be observed that the adsorption of CPC decreased gradually with an increasing $\mathrm{pH}$. In the presence of each of the three depressants, CPC adsorption was lower than that without the depressants, but the difference was not more significant. The effects of the three depressants on the adsorption of CPC on the surface of molybdenum oxide followed the order tartaric acid $>$ sodium hexametaphosphate $>$ sodium silicate.

Figure 3 shows the effects of depressants on the adsorption of CPC on the surface of fluorapatite under different $\mathrm{pH}$ conditions. It can be observed that the adsorption of CPC increased gradually with increasing $\mathrm{pH}$, regardless of the type of depressant used. When the $\mathrm{pH}$ was higher than 7 , the amount of adsorption increased more rapidly, which may have been caused by the activation of fluorapatite at the higher $\mathrm{pH}$ values. Table 1 shows that the fluorapatite anion content increased under alkaline conditions, which enhanced the adsorption of CPC onto the mineral surface. The amount of adsorption was lower in the presence of depressants than in the absence of inhibitors over the entire $\mathrm{pH}$ range. The effects of the three depressants on the adsorption capacity of CPC on the fluorapatite surface were ranked as follows: sodium hexametaphosphate $>$ tartaric acid $>$ sodium silicate. 


\subsection{Infrared Spectroscopic Measurement}

To investigate the adsorption mechanism of sodium hexametaphosphate on molybdenum oxide, the infrared spectra of molybdenum oxide before and after the interaction with sodium hexametaphosphate were analyzed and are shown in Figure 4.

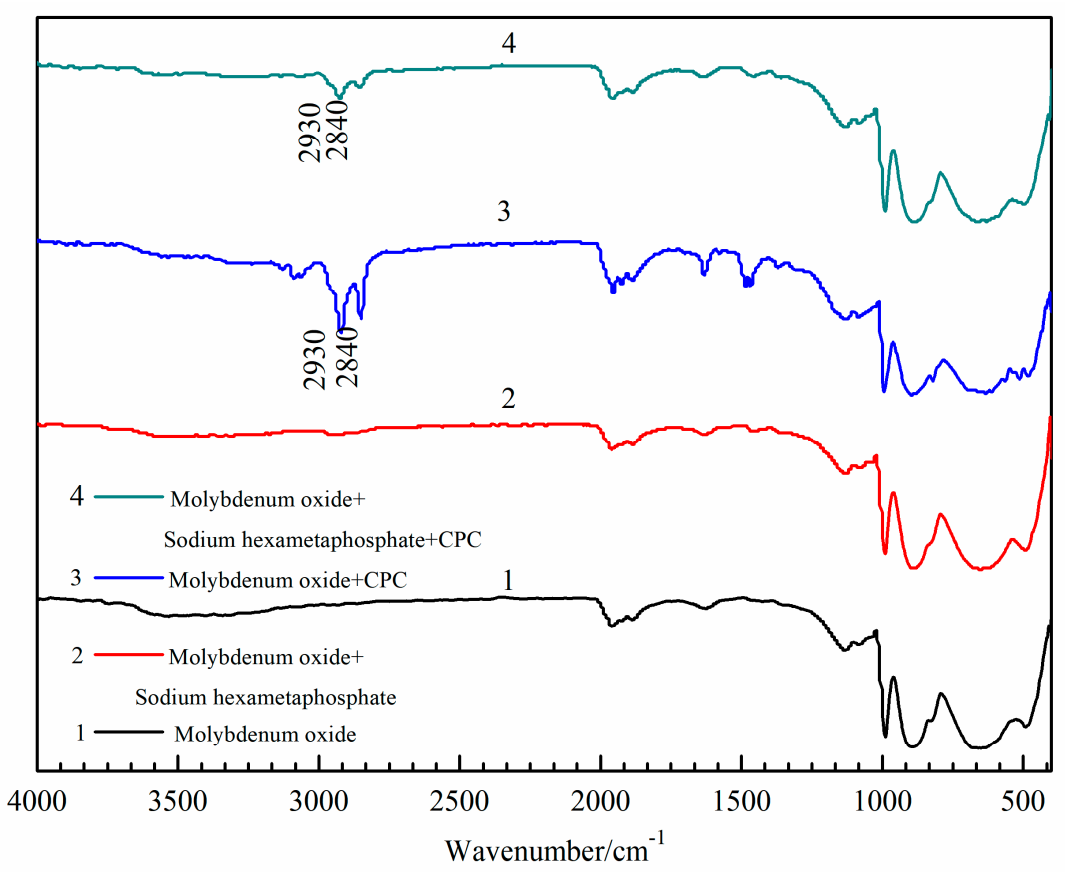

Figure 4. Infrared spectral of molybdenum oxide after its interaction with CPC and sodium hexametaphosphate.

The spectrum of molybdenum oxide (Spectrum (1)) shows characteristic bands at $988.9 \mathrm{~cm}^{-1}, 879.6 \mathrm{~cm}^{-1}$, and $490 \mathrm{~cm}^{-1}$, which were attributed to the stretching vibrations of $\mathrm{Mo}-\mathrm{O}_{1}, \mathrm{Mo}-\mathrm{O}_{2}$, and $\mathrm{Mo}-\mathrm{O}_{3}$, respectively $[19,20]$.

After interacting with sodium hexametaphosphate, spectrum (2) was obtained, which exhibited no noticeable changes. As the flotation tests on individual minerals showed that sodium hexametaphosphate inhibited molybdenum oxide, which may be due to the physical adsorption of sodium hexametaphosphate on the surface of molybdenum oxide, Spectrum (3) shows the absorption bands at $2840 \mathrm{~cm}^{-1}$ and $2930 \mathrm{~cm}^{-1}$, which were the characteristic of $-\mathrm{CH}_{2}-$ and $-\mathrm{CH}_{3}$, indicating that the adsorption of $\mathrm{CPC}$ occurred on the molybdenum oxide surface. However, the absorption bands become weaker in spectrum (4), indicating that sodium hexametaphosphate reduced the adsorption of CPC on the surface of molybdenum oxide; however, based on the flotation tests of molybdenum oxide, the depression was very weak.

To investigate the adsorption mechanism of sodium hexametaphosphate on fluorapatite, the infrared spectra of fluorapatite before and after the addition of sodium hexametaphosphate were analyzed and are shown in Figure 5.

The spectrum of fluorapatite (spectrum (1)) shows characteristic bands at $1060 \mathrm{~cm}^{-1}$, $964 \mathrm{~cm}^{-1}, 600 \mathrm{~cm}^{-1}$, and $471 \mathrm{~cm}^{-1}$, which were attributed to the stretching vibration of $\mathrm{PO}_{4}{ }^{3-}$ [21].

After interacting with sodium hexametaphosphate, Spectrum (2) was obtained, which again exhibited no noticeable changes. Due to the fact that the flotation tests on individual minerals showed that sodium hexametaphosphate inhibited fluorapatite, its adsorption on the surface of fluorapatite was identified as physical absorption. Spectrum (3) shows absorption bands at $2840 \mathrm{~cm}^{-1}$ and $2930 \mathrm{~cm}^{-1}$, which were attributed to the stretching vibration modes of $-\mathrm{CH}_{2}-$ and $-\mathrm{CH}_{3}$, indicating that the adsorption of $\mathrm{CPC}$ occurred on the fluorapatite surface. Spectrum (4) is nearly identical to spectrum (3). The flotation 
tests on fluorapatite showed that the interaction between CPC and fluorapatite was very weak; therefore, the depression of CPC adsorption on the surface of fluorapatite with the addition of sodium hexametaphosphate was not distinctly indicated from the infrared spectrograms.

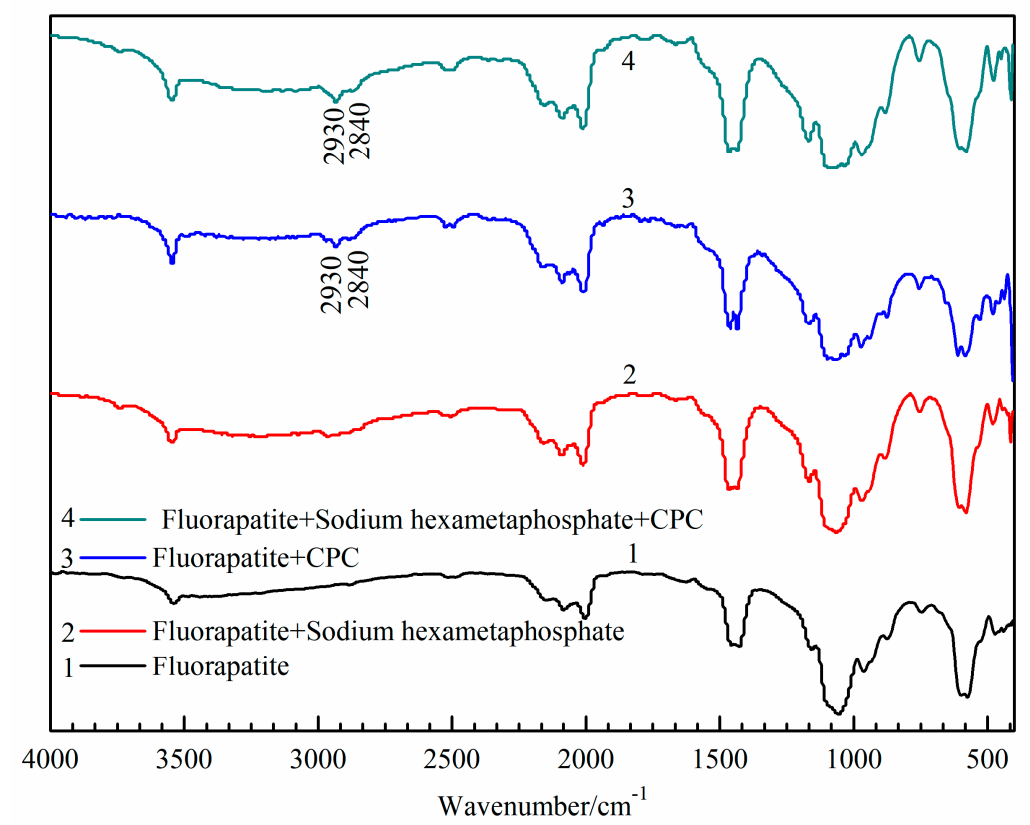

Figure 5. Infrared spectra of fluorapatite before and after its interaction with CPC and sodium hexametaphosphate.

\subsection{Zeta Potential Measurements}

To further illustrate the effect of sodium hexametaphosphate on the surface properties of molybdenum oxide and fluorapatite, the surface potentials before and after interaction with sodium hexametaphosphate were measured. Figure 6 shows the effect of sodium hexametaphosphate on the surface zeta potential of molybdenum oxide. After interacting with sodium hexametaphosphate, the surface zeta potential of molybdenum oxide was changed only slightly; therefore, the observed effect was insignificant. Figure 7 shows the effect of sodium hexametaphosphate on the surface zeta potential of fluorapatite, whose isoelectric point is approximately 4.1. The surface zeta potential of fluorapatite was decreased after adding sodium hexametaphosphate, and no point of zero charges was observed in this case at the tested $\mathrm{pH}$ values. When the $\mathrm{pH}$ was 4 , the surface zeta potential of fluorapatite decreased from +0.6 to approximately -12 , and the potential became more negative. Moreover, by comparing the surface zeta potentials of fluorapatite and molybdenum oxide after the interaction with sodium hexametaphosphate, it can visibly be seen that when the $\mathrm{pH}$ was above five, the repulsive forces between molybdenum oxide and fluorapatite were increased in magnitude, which could provide the effective separation between these minerals. 


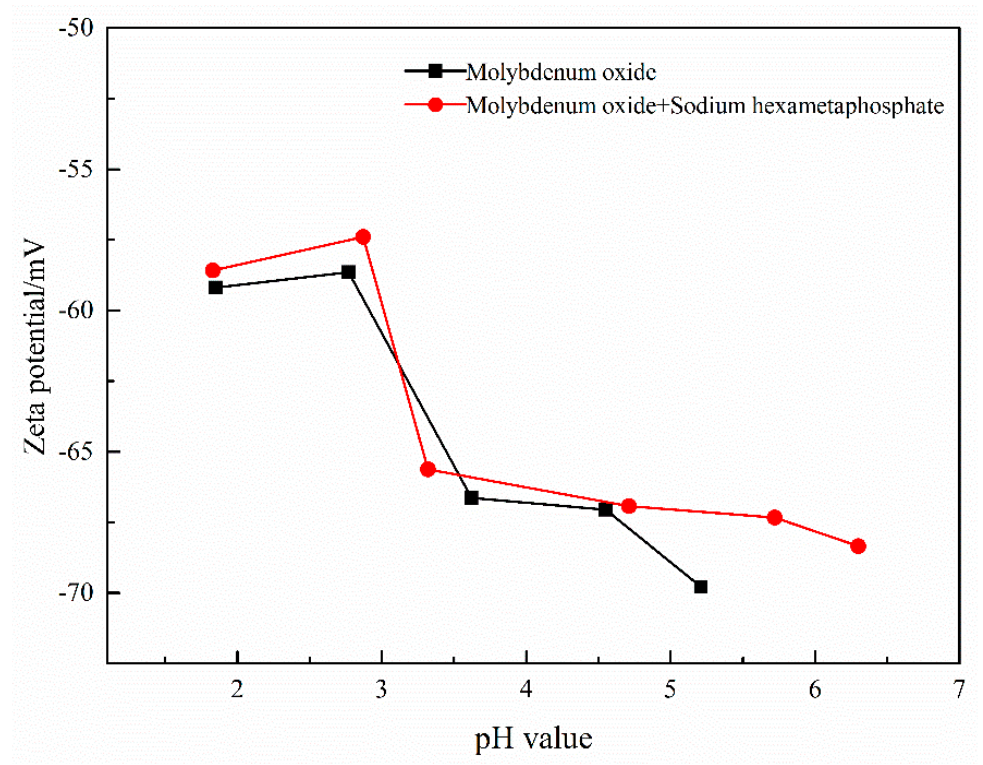

Figure 6. Relationship between $\mathrm{pH}$ and zeta potential values on the surface of molybdenum oxide before and after the addition of sodium hexametaphosphate.

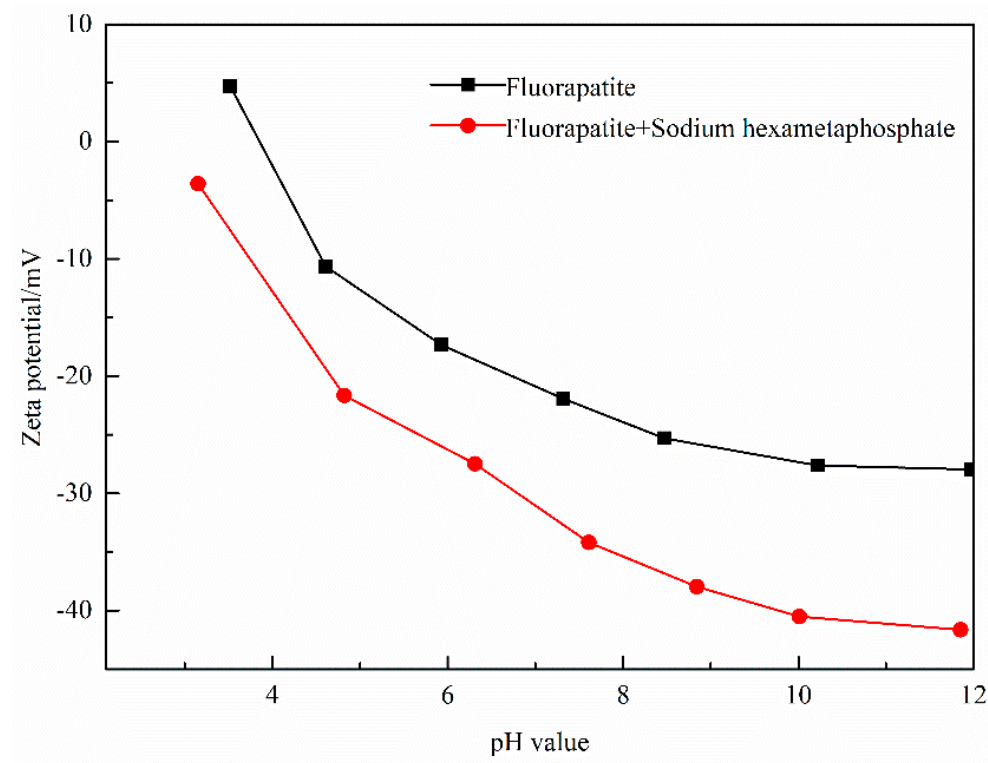

Figure 7. Relationship between $\mathrm{pH}$ and zeta potential values on the surface of fluorapatite before and after the addition of sodium hexametaphosphate.

\section{Conclusions}

In this research work, the depression effects of different depressants such as sodium silicate, sodium hexametaphosphate, and tartaric acid were investigated, aiming at obtaining the more appropriate depressant in flotation separation of molybdenum oxide from fluorapatite. Major conclusions are summarized as follows:

(1) Sodium hexametaphosphate, tartaric acid, and sodium silicate all have a much greater depression effect on fluorapatite than molybdenum oxide, the strongest depression effect on fluorapatite compared with other depressants, reducing the flotation recovery of fluorapatite as low as less than $20 \%$.

(2) Sodium hexametaphosphate significantly reduced the adsorption of CPC onto the fluorapatite surface. These results were in good agreement with the flotation tests. The addition of sodium hexametaphosphate reduced the intensities of the characteristic adsorption peaks of CPC on the fluorapatite surface. On the other hand, sodium 
hexametaphosphate showed little effect on the adsorption of CPC onto the surface of molybdenum oxide. However, the sodium hexametaphosphate underwent physical absorption to varying degrees on the surfaces of molybdenum oxide and fluorapatite.

(3) The zeta potential results showed that the sodium hexametaphosphate greatly altered the surface characteristics of fluorapatite by decreasing its surface charges. These results further indicated that the addition of sodium hexametaphosphate increased the magnitudes of the repulsive forces between molybdenum oxide and fluorapatite, which could provide an effective separation between these minerals.

Sodium hexametaphosphate was a potential depressant in the flotation separation of molybdenum oxide from fluorapatite with CPC as the collector.

Author Contributions: Conceptualization, J.L. and Z.L.; methodology, J.L., B.P. and F.B.; software, Z.L.; validation, J.L., B.P. and F.B.; formal analysis, L.Z.; investigation, L.Z.; resources, J.L.; data curation, B.P.; writing—original draft preparation, J.L.; writing—review and editing, Z.L.; visualization, J.L.; supervision, Z.L.; project administration, J.L.; funding acquisition, J.L. All authors have read and agreed to the published version of the manuscript.

Funding: This work was funded by the Natural Science Foundation of Hunan Province, No.2018JJ3446 and the Scientific research project of Hunan Provincial Department of Education project, No.17C1374.

Conflicts of Interest: The authors declare no conflict of interest.

\section{References}

1. Zhao, Z.; Li, J.; Cao, C.; Huo, G.; Zhang, G.; Li, H. Recovery and purification of molybdenum from Ni-Mo ore by direct air oxidation in alkaline solution. Hydrometallurgy 2010, 103, 68-73. [CrossRef]

2. Fan, D.; Zhang, T.; Ye, J.; Pašava, J.; Kribek, B.; Dobes, P.; Varrin, I.; Zak, K. Geochemistry and origin of tin-polymetallic sulfide deposits hosted by the Devonian black shale series near Dachang, Guangxi, China. Ore Geol. Rev. 2004, 24, 103-120. [CrossRef]

3. Wang, S.-F.; Wei, C.; Deng, Z.-G.; Li, C.-X.; Li, X.-B.; Wu, J.; Wang, M.-S.; Zhang, F. Extraction of molybdenum and nickel from Ni-Mo ore by pressure acid leaching. Trans. Nonferr. Metal. Soc. 2013, 23, 3083-3088. [CrossRef]

4. Liu, J.D.; Sun, W. Flotation technology and adsorption mechanism of collector CSU-M to molybdenum oxide in Ni-Mo ore. J. Cent. South Univ. 2014, 45, 4105-4110.

5. Peng, J.; Wang, X.; Jiang, C.; Wang, M.; Ma, Y.; Xiang, X. Separation of Mo(VI) and Fe(III) from the acid leaching solution of carbonaceous Ni-Mo ore by ion exchange. Hydrometallurgy 2014, 142, 116-120. [CrossRef]

6. Xian, P.-F.; Zhou, S.-F.; Wang, M.-Y.; Wang, X.-W.; Chen, B.-F. Extraction of molybdenum and nickel from roasted Ni-Mo ore by hydrochloric acid leaching, sulphation roasting and water leaching. Trans. Nonferr. Metal. Soc. 2017, 27, 220-226. [CrossRef]

7. Wang, M.-S.; Wei, C.; Fan, G.; Deng, Z.-G.; Wang, S.-F.; Wu, J. Molybdenum recovery from oxygen pressure water leaching residue of Ni-Mo ore. Rare Met. 2013, 32, 208-212. [CrossRef]

8. Deng, Z.G.; Bai, J.Y.; Wei, C.; Fan, G.; Li, X.; Li, M.; Li, C. Pressure-Leaching Behavior of Nickel from Ni-Mo Ore in Aqueous Oxygenated Media. Int. J. Chem. React. Eng. 2018, 16, 20170209.

9. Gadd, M.G.; Peter, J.; Jackson, S.E.; Yang, Z.; Petts, D. Platinum, Pd, Mo, Au and Re deportment in hyper-enriched black shale Ni-Zn-Mo-PGE mineralization, Peel River, Yukon, Canada. Ore Geol. Rev. 2019, 107, 600-614. [CrossRef]

10. Orberger, B.; Vymazalova, A.; Wagner, C.; Fialin, M.; Gallien, J.P.; Wirth, R.; Pasava, J.; Montagnac, G. Biogenic origin of intergrown Mo-sulphide and carbonaceous matter in Lower Cambrian black shales (Zunji Formation, S China). Chem. Geol. 2007, 238, 213-231. [CrossRef]

11. Chen, Y.; Chen, X.M.; Peng, Y. The effect of sodium hydrosulfide on molybdenite flotation in seawater and diluted seawater. Miner. Eng. 2020, 158, 106589. [CrossRef]

12. Zeng, L.; Xiao, L.S.; Xiao, C.L.; Gong, B.F. Study on leaching of molybdenum and nickel from Ni-Mo ore using sodium chlorate. Can. Metall. Quart. 2013, 52, 335-341. [CrossRef]

13. Wang, M.; Chen, B.; Huang, S.; Yang, H.; Hu, B.; Zhang, C.; Wang, X.; Xu, Y. Extraction of molybdenum and nickel from Ni-Mo ore by acid leaching combined with chlorate oxidation and phosphate complexation. Miner. Eng. 2018, 124, 63-67. [CrossRef]

14. Xu, L.; Lehmann, B.; Mao, J. Seawater contribution to polymetallic Ni-Mo-PGE-Au mineralization in Early Cambrian black shales of South China: Evidence from Mo isotope, PGE, trace element, and REE geochemistry. Ore Geol. Rev. 2013, 52, 66-84. [CrossRef]

15. Dong, L.; Jiao, F.; Qin, W.; Wei, Q. Utilization of iron ions to improve the depressive efficiency of tartaric acid on the flotation separation of scheelite from calcite. Miner. Eng. 2021, 168, 106925. [CrossRef]

16. Abdel-Khalek, N.A. Evaluation of flotation strategies for sedimentary phosphates with siliceous and carbonates gangues. Miner. Eng. 2000, 13, 793. [CrossRef]

17. Chander, H.S. Reagents used in the flotation of phosphate ores: A critical review. Miner. Eng. 2003, 16, 577-585. 
18. Yepsen, R.; Roa, J.; Toledo, P.; Gutiérrez, L. Chalcopyrite and Molybdenite Flotation in Seawater: The Use of Inorganic Dispersants to Reduce the Depressing Effects of Micas. Minerals 2021, 11, 539. [CrossRef]

19. Rammal, M.B.; Omanovic, S. Synthesis and characterization of $\mathrm{NiO}, \mathrm{MoO}_{3}$, and $\mathrm{NiMoO}_{4}$ nanostructures through a green, facile method and their potential use as electrocatalysts for water splitting. Mater. Chem. Phys. 2020, 255, 123570. [CrossRef]

20. Hu, H.; Deng, C.; Xu, J.; Zhang, K.; Sun, M. Metastableh- $\mathrm{MoO}_{3}$ and stable $\alpha-\mathrm{MoO}_{3}$ microstructures: Controllable synthesis, growth mechanism and their enhanced photocatalytic activity. J. Exp. Nanosci. 2015, 10, 1336-1346. [CrossRef]

21. Lei, Z.; Cagnetta, G.; Li, X.; Qu, J.; Li, Z.; Zhang, Q.; Huang, J. Enhanced adsorption of potassium nitrate with potassium cation on H3PO4 modified kaolinite and nitrate anion into Mg-Al layered double hydroxide. Appl. Clay Sci. 2018, 154, 10-16. [CrossRef] 